\title{
Multipl kutanöz ve Uterin Leiyomiyomatozis sendromu (Reed sendromu)
}

\section{Özet}

Kutanöz leiyomiyomlar düz kas hücrelerinden köken alan, derinin nadir görülen tümörleridir. Kutanöz leiyomiyomatosis ile uterus leiyomiyomlarının birlikteliği ile renal hücreli kanserin de eşlik edebildiği sendrom "multipl kutanöz ve uterin Leiomyomatozis sendromu (Reed sendromu)" şeklinde adlandırımaktadır. Kırk beş yaşında kadın, gövdede ağrılı şişlikler şikayetiyle polikliniğimize başvurdu. Özgeçmişinde Tip 2 diyabetes mellitus ve multipl uterin leiyomiyomlar nedeniyle histerektomi operasyonu mevcuttu. Dermatolojik muayenede gövdede bilateral lomber bölgelerde yerleşen grube, sağ kol ve sırtta birkaç adet, dokunmakla hassas, deri renginde-kırmızımsı, infiltre papülonodüler lezyonlar görüldü. Papüllerden alınan biyopsinin histopatolojik incelemesi leiyomiyom ile uyumluydu. Hastaya ağrılarına yönelik gabapentin tedavisi başlandı ve bir ay sonundaki kontrolde ağrılarda azalma gözlendi. (Türkderm 2014; 48: 105-7)

Anahtar Kelimeler: Leiyomyomatozis, kutanöz, uterin, gabapentin, ağıı

\section{Summary}

Cutaneous leiomyomas are rare benign tumors arising from smooth muscle cells. The combination of cutaneous leiomyomatosis, uterine leiomyomatosis and renal cell cancer is referred to as "multiple cutaneous and Uterine Leiomyomatosis syndrome (Reed's syndrome)". A forty-five-year-old female patient was admitted to our clinic with multiple painful bumps on the body. Diabetes mellitus and hysterectomy operation due to leiomyoma were present in her past medical history. Dermatologic examination revealed multiple, painful, skin coloured-red papulonodules forming clusters on the bilateral lumbar region and a few lesions on the right arm and back. Histopathological examination of the biopsy specimen revealed leiomyoma. Gabapentin therapy was initiated and in the one-month follow-up, it was observed that she had relief from pain. (Turkderm 2014; 48: 105-7)

Key Words: Leiomyomatosis, gabapentin, cutaneous, uterine, pain

\section{Giriş}

Kutanöz leiyomiyomlar düz kas hücrelerinden köken alan, derinin nadir görülen tümörleridir. Orijinlerine göre; kıl folikülündeki erektör pili kasından köken alanlar (piloleiyomiyom), vasküler düz kas hücrelerinden köken alanlar (anjioleiyomiyom) ve genital bölgedeki düz hücrelerinden köken alanlar (dartoik) olarak sınıflandırıırlar1,2.

Piloleiyomiyomlar, diğer tiplerin aksine multipl lezyonlar ile prezente olurlar ve leiyomiyomatozis olarak adlandırılırlar.
Multipl lezyonlar lineer, zosteriform veya segmental dağılım gösterebilirler ${ }^{1,3}$.

Kutanöz leiyomiyomatosis ile uterus leiyomiyomlarının birlikteliği ile renal hücreli kanserin de eşlik edebildiği sendrom "multipl kutanöz ve uterin leiomyomatozis sendromu (Reed sendromu)" şeklinde adlandırımaktadır1.

Burada multipl kutanöz ve uterin leiomyomatozis sendromu olan ve gabapentin ile ağrı kontrolü sağlanan bir olgu sunulmaktadır.

Yazışma Adresi/Address for Correspondence: Dr. Hilal Kaya Erdoğan, Ahi Evran Üniversitesi Eğitim ve Araşıırma Hastanesi, Dermatoloji Kliniği, Kırşehir, Türkiye Tel.: +90 3862134515 E-posta: hilalkayaerdogan@yahoo.com Geliş Tarihi/Received: 16.12.2013 Kabul Tarihi/Accepted: 14.01.2014 


\section{Olgu Sunumu}

Kırk beş yaşında kadın, gövdede ağrılı şişlikler şikayetiyle polikliniğimize başvurdu. Hasta beş yıldır olan bu lezyonların özellikle soğukla birlikte ağrıdığını tarifliyordu. Tip 2 diyabetes mellitus tanısıyla oral antidiyabetikler kullanan hasta, multipl uterin leiyomiyomlar nedeniyle histerektomi operasyonu geçirmişti. Soygeçmişi sorgulandığında ailesinde benzer deri hastalığı olan yoktu, ancak kız kardeşinde de multipl uterin leiyomiyomlar nedeniyle histerektomi operasyonu öyküsü mevcuttu.

Dermatolojik muayenede gövdede bilateral lomber bölgelerde yerleşen grube, sağ kol ve sırtta birkaç adet, dokunmakla hassas, deri renginde kırmızımsı, infiltre papülonodüler lezyonlar görüldü (Şekil 1 ve 2).

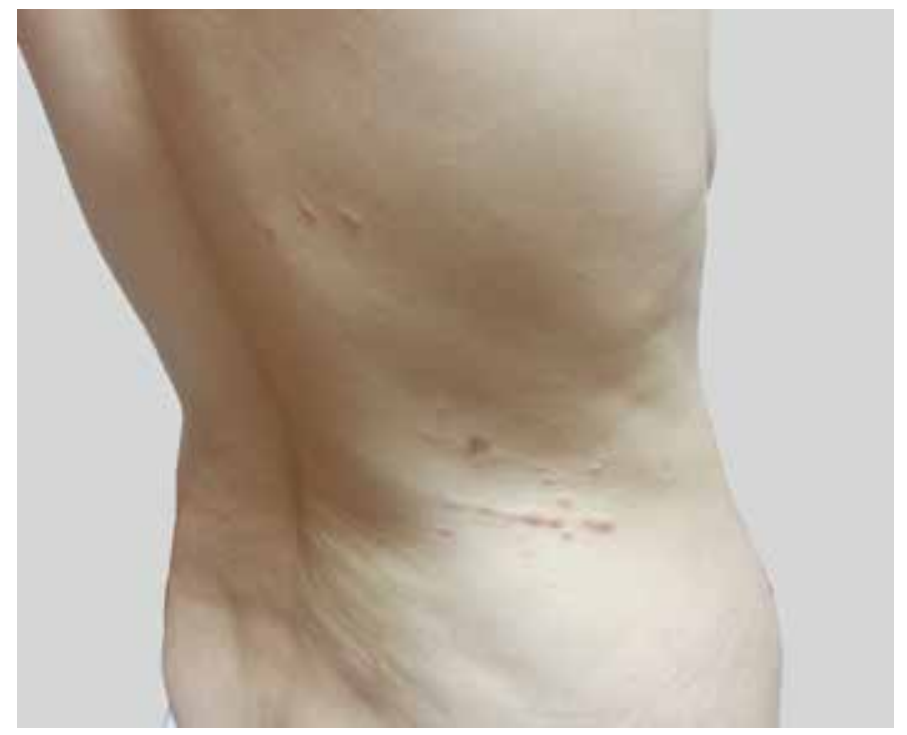

Şekil 1. Sağ lomber bölgede grube, deri renginde-kırmızımsı, infiltre papülonodüller

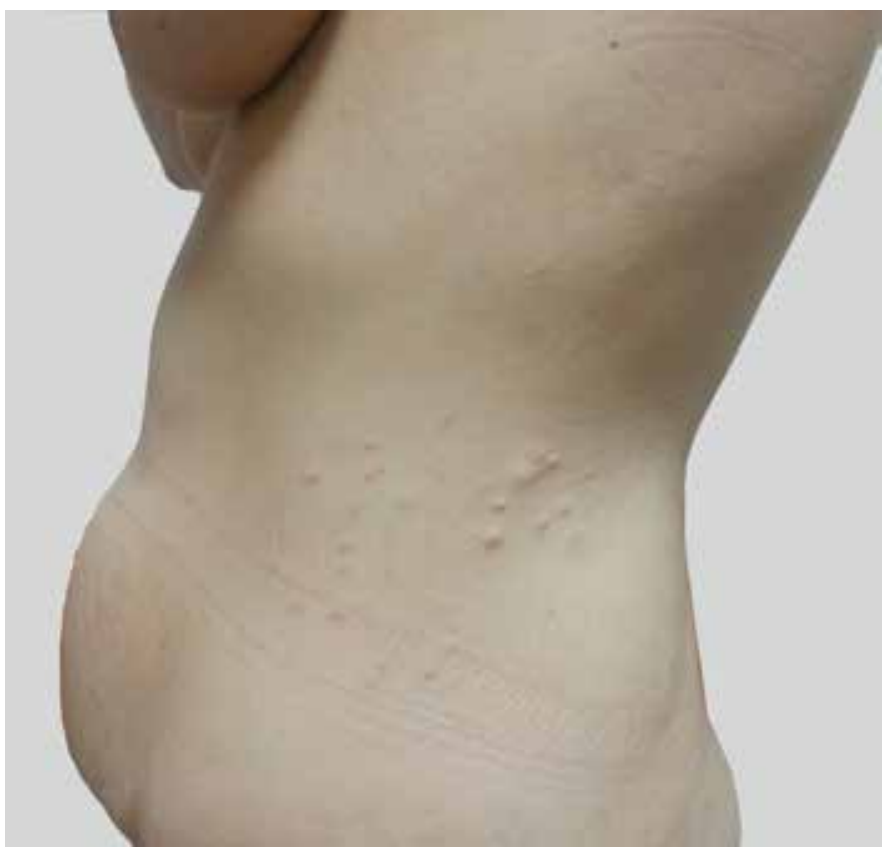

Şekil 2. Sol lomber bölgede multipl papülonodüller
Hastanın fizik muayenesinde ve sistem sorgulamasında patoloji saptanmadı. Yapılan hemogram ve biyokimyasal incelemeler hiperglisemi dışında normal sınırlardaydı. Nefroloji konsültasyonu sonucu erken evre diyabetik nefropati dışında patoloji saptanmadı. Abdomen ultrasonografi incelemesi de normaldi.

Papüllerden alınan biyopsinin histopatolojik incelemesinde, dermiste spindle hücrelerin birbirleriyle kesişen demetler oluşturduğu neoplastik proliferasyon izlendi. Atipi ve mitoz yoktu. Yapılan immünohistokimyasal çalışmalarda aktin ve desmin ile neoplastik hücrelerde boyanma izlendi, S-100 ile boyanma saptanmadı (Şekil 3 ve 4).

Hastanın çok sayıda lezyonu olduğu için eksizyon yapılamadı. Hastaya ağrılarına yönelik gabapentin tedavisi başlandı ve bir ay sonundaki kontrolde ağrılarda azalma gözlendi.

\section{Tartışma}

Kutanöz leiyomiyomlar genellikle 20-40 yaşları arasında, gövde ve ekstremitelerde, deri renginde, kırmızı-kahverengi papül ve nodüller şeklinde gözlenir. Soğuk ve basınç ile ağrılı olması tipik özelliklerindendir 1,4 .

Literatürde otozomal dominant kalıtım paternine sahip ailesel kutanöz leiyomiyomatozis olguları bildirilmiştir. 1973 ylında Reed ve ark. kutanöz leiyomiyomatosis ile uterus leiyomiyomlarının birlikteliğini bildirmişlerdir. Renal hücreli kanserin de eşlik edebildiği bu sendrom günümüzde multipl kutanöz ve uterin leiomyomatozis sendromu şeklinde adlandırılmaktadır ${ }^{1,5}$.

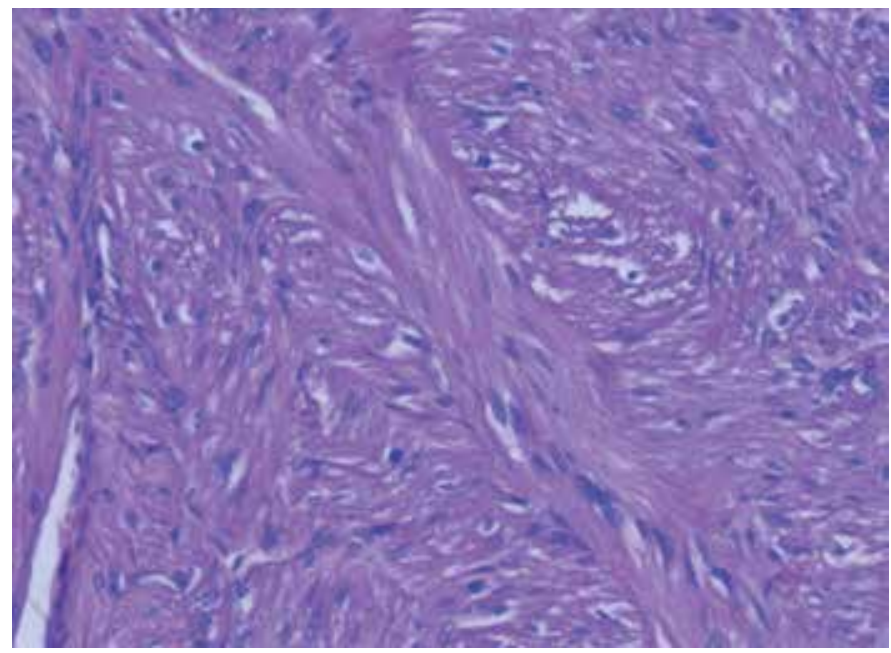

Şekil 3. Dermiste spindle hücrelerin birbirleriyle kesişen demetler oluşturduğu neoplastik proliferasyon

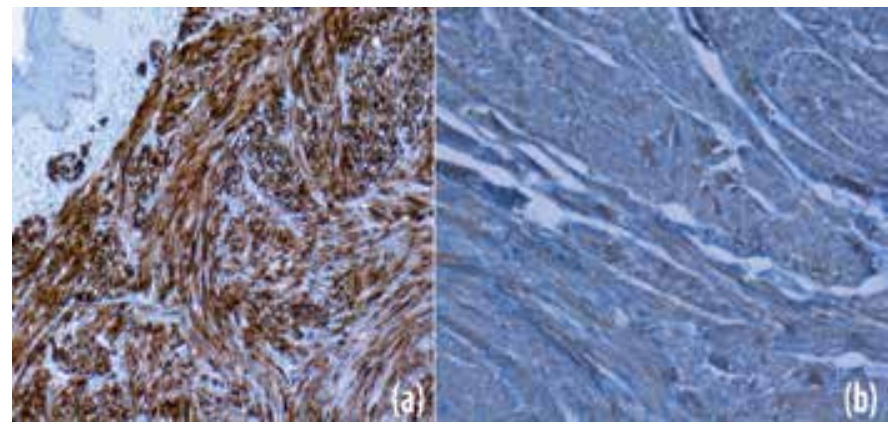

Şekil 4. (a) Desmin ve (b) aktin ile neoplastik hücrelerde boyanma 
Sendromik olan bu vakalarda fumarat hidrataz germ mutasyonu saptanmıştır. Fumarat hidrataz Krebs döngüsündeki aktif enzimlerden biridir ve tümör supresyon geni olduğu düşünülmektedir. Son yıllardaki çalışmalarda uterin ve kutanöz leiyomyomatosis vakalarının \%55\%83'ünde bu mutasyon gösterilmiştir6,7.

Kütanöz leiyomiyomlar benin lezyonlar olmasına karşın, altta yatan bir malinitenin habercisi olabilecekleri için bu hastalarda multidisipliner yaklaşım önemlidir. Reed senromu olan hastalarda gelişen renal hücreli karsinomun agresif seyirli olması nedeniyle, özellikle de aile öyküsü pozitif olan hastalara abdominal görüntüleme yöntemleri ile tarama yapılabilir5,8,9. Öte yandan kutanöz leiyomiyomlarda, diğer leiyomiyomlarda olduğu gibi nadiren leiyomyosarkom gelişimi de bildirilmiştir 10,11.

Soliter leiyomiyomların tedavisinde eksizyon yapılmaktadır. Multipl lezyonları olan hastalarda ise ağrıya yönelik tedaviler planlanmalıdır. Ağıı patologenezi sinir liflerinin kompresyonu, tümoral kasların kasılması veya erektör pili kası üzerinde bulunan alfa adrenerjik reseptörlerin uyarılması ile açıklanmaktadır1,2,4. Ağrıyı azaltmak için kalsiyum kanal blokerleri (örn; nifedipin), gabapentin, hidrobromid, nitrogliserin, fenoksibenzamin, alfa adrenerjik reseptör blokerleri gibi farmakolojik ajanların yanında kriyoterapi, karbondioksit lazer ablasyonu, iyontoforez, botilinyum toksin injeksiyonu, intralezyonel steroid injeksiyonu gibi tedaviler denenmektedir 10,12-15.

Gabapentin santral sinir sistemindeki GABA reseptörüne bağlanarak reseptörün GABA'ya olan ilgisini arttıır. Hastamıza ağrının nöropatik doğası da düşünülerek gabapentin tedavisi verilmiş ve bir ayın sonunda ağrıda azalma gözlenmiş̧ir10,13. Bizim olgumuz gibi total eksizyonun yapılamadığı olgularda gabapentin ağrının azaltılması ve yaşam kalitesinin arttırımasında önemli bir seçenek olarak akılda tutulmalıdır.

\section{Kaynaklar}

1. Badeloe S, Frank J: Clinical and molecular genetic aspects of hereditary multiple cutaneous leiomyomatosis. Eur J Dermatol 2009;19:545-51.

2. Ghanadan A, Abbasi A, Kamyab Hesari K: Cutaneous leiomyoma: novel histologic findings for classification and diagnosis. Acta Med Iran 2013;51:19-24.

3. Malhotra P,Walia H, Singh A, Ramesh V: Leiomyoma cutis: a clinicopathological series of 37 cases. Indian J Dermatol 2010;55:337-41.

4. Ürkmez A, Ertam I, Karaarslan IK, Kazandı A, Ceylan C: Leiyomyomatozis Kutis. Turk J Dermatol 2011;5:101-3.

5. Emer JJ, Solomon S, Mercer SE: Reed's Syndrome: A Case of Multiple Cutaneous and Uterine Leiomyomas. J Clin Aesthet Dermatol 2011;4:37-42.

6. Hayedeh G, Fatemeh M, Ahmadreza R, Masoud A, Ahmad S: Hereditary leiomyomatosis and renal cell carcinoma syndrome: a case report. Dermatol Online J 2008;14:16.

7. Kim G: Multiple cutaneous and uterine leiomyomatosis (Reed's syndrome). Dermatol Online J 2005;11:21.

8. Deveci U, Kapakli MS, Altintoprak F, Cayırcı M, Manukyan MN, Kebudi A: Bilateral nipple leiomyoma. Case Rep Surg 2013;2013:475215.

9. Choudhary S, McLeod M, Torchia D, Romanelli P: Multiple cutaneous and uterine leiomyomatosis syndrome: a review. J Clin Aesthet Dermatol 2013;6:16-21.

10. Smith G, Heidary N, Patel R, et al: Cutaneous piloleiomyomata. Dermatol Online J. 2009;15:10.

11. Fons ME, Bachhuber T, Plaza JA: Cutaneous leiomyosarcoma originating in a symplastic pilar leiomyoma: a rare occurrence and potential diagnostic pitfall. J Cutan Pathol 2011;38:49-53.

12. Aggarwal S, De D, Kanwar AJ, Saikia UN, Khullar G, Mahajan R: Disseminated cutaneous leiomyomatosis treated with oral amlodipine. Indian J Dermatol Venereol Leprol 2013;79:136.

13. Alam $M$, Rabinowitz $A D$, Engler $D E:$ Gabapentin treatment of the multiple piloleiomyoma-related pain. J Am Acad Dermatol 2002;46:27-9.

14. Sifaki MK, Krueger-Krasagakis S, Koutsopoulos A, Evangelou GI, Tosca AD: Botulinum toxin type A-treatment of a patient with multiple cutaneous piloleiomyomas. Dermatology 2009;218:44-7.

15. Liu C, Tang ZH, Bei H, Zeng HY: Treatment of a patient with multiple cutaneous piloleiomyoma-related pain with a local injection of triamcinolone acetonide. Dermatology 2013;227:52-4. 